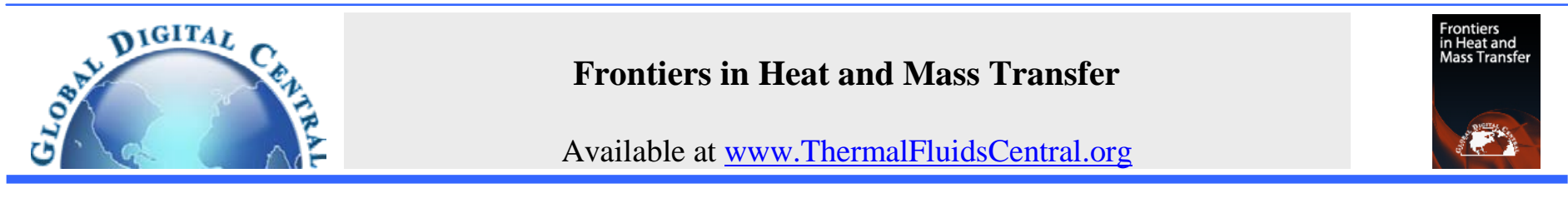

\title{
NUMERICAL STUDY OF 3D THERMAL AND HYDRAULIC CHARACTERISTICS OF WAVY FIN AND TUBE HEAT EXCHANGER
}

\author{
Arafat A. Bhuiyan ${ }^{\mathrm{a}, 1}$, A. K. M. Sadrul Islamª, M. Ruhul Amin ${ }^{\mathrm{b}}$ \\ ${ }^{a}$ Department of Mechanical Engineering, Islamic University of Technology, Board Bazar, Gazipur-1704, Bangladesh \\ ${ }^{b}$ Department of Mechanical and Industrial Engineering, Montana State University, Bozeman, MT 59717, USA
}

\begin{abstract}
This numerical analysis presents the airside performance of a wavy fin-and-tube heat exchanger having 4 row configurations considering steady, incompressible and 3D flow using Commercial CFD Code ANSYS CFX 12.0. Results are presented in the form of friction factor (f), Colburn factor (j) and efficiency index (j/f). The numerical procedure has been validated by comparison with published numerical and experimental results and good agreement has been observed. A series of numerical calculations have been carried out in order to analyze the influence of various geometric characteristics on different fields as well as on the heat transfer and pressure drop and efficiency within a heat exchanger. The effects of longitudinal pitch (Ll), transverse pitch (Lt), Fin Pitch (Fp), wavy angle (Wa) and inlet flow angle ( $\alpha$ ) on wavy fin-and-tube heat exchanger are studied. Different inlet flow angles such as ${ }^{\circ},+17.5^{\circ},-17.5^{\circ},+35^{\circ}$ and $-35^{\circ}$ are employed normal to the face of the heat exchanger in order to investigate the performance of inlet flow angles. There is a strong correlation between the response of the flow efficiency, pressure drop and heat transfer performance to these parameters.
\end{abstract}

Keywords: Friction factor; Colburn factor; efficiency index; longitudinal pitch; transverse pitch; fin pitch; wavy angle.

\section{INTRODUCTION}

Fin-and-tube heat exchangers are frequently used in the process and HVAC\&R industries which consist of a group of fins set parallel to one another at prearranged spacing. In level headed applications the principal thermal resistance for an air-cooled heat exchanger is usually on the air side which may account for $85 \%$ or more of the total resistance (Wang et al., 1997). In order to get better thermal performance and also to considerably reduce the dimension and weight of air cooled heat exchangers that is to improve the overall heat transfer performance, the use of enhanced surfaces is very well-liked in air cooled heat exchangers. (Kays and London, 1984) provide the most comprehensive design database though it is containing comparatively older information. Wavy or corrugated fins are exceptionally popular fin patterns that are urbanized to improve the heat transfer performance. It is advantageous to use wavy surface as it can lengthen the flow path of the airflow and thus cause better air flow mixing. As a result, higher heat transfer performance is expected compared to the other plate fin surface. In the present study wavy fin is considered for the determination of the performance in the fin-and tube heat exchangers.

For wavy fin having circular tube configurations, extensive experimental data were reported in the literature on the fluid flow and heat transfer characteristics. Correlations were also proposed for those characteristics by the researchers. Beecher et al. has done the first comprehensive study (Beecher and Fagan, 1987) and projected correlations for predicting the Colburn factor (j) and the friction factor (f) based on this study was proposed by Kim. (Kim et al., 1996). Several experiments were performed for the convective heat transfer in 2D channel as mentioned in the literature (Ali and Ramadhyani, 1992), (Snyder and Wirtz, 1993). Also a lot of experiments were performed to settle on the heat transfer and pressure drop characteristics of 3D wavy fin-and-tube heat exchangers as documented in (Wang, 1997), (Wang, 1995), (Wang, 1998), (Wang, 1999), (Yan, 2000). They also gave correlations for use in describing the Colburn factor and friction factor.
(Wang et al. 2002) proposed the most updated heat transfer coefficient and friction factor correlations wavy fin-and-tube heat exchangers.

In addition to the experimental study, there are also some numerical investigations for the wavy fin heat exchangers. These investigations provided valuable information of the fundamental phenomenon of the fin geometry. Since wavy fin heat exchangers are widely used in the industry, the ability of numerical codes to predict the thermal/hydraulic performance of these surfaces is of substantial attention. But most of previous numerical studies were 2D in nature and assume laminar flow for the wavy conduit. (Asako, 1987), (Amano, 1985), (Nishimura, 1987), (Xin, 1988), (Patel, 1991), (Rutledge, 1994), (Yang, 1997). However only a few researchers have used 3-D simulations when side wall effects are important, as in tube banks with fins (McNab, 1996), (Jang, 1997). There are many factors that have an effect on the heat transfer from the heat exchangers as well as pressure drop across it. The effect of geometrical parameters on the operation of the fin-tube heat exchanger has not so far explored in details. Few experimental data is available which explores the effects of Wavy angle (Wa) though this parameter is important which determine the heat transfer and pressure drop characteristics. The numerical study by (Jang et al. 1997) explores the effect of these parameters on the performance of the wavy-fin configuration. (Panse, 2005) explores the effects of wavy angle and wavy height for the wavy fin staggered configuration for the transitional flow range.

Most of the previous numerical investigations assumed that the inlet flow is normal to the heat exchanger face. The experimental studies carried out by (Guo and Tafti, 2003) revealed that there is a strong correlation between the response of the flow efficiency and the heat transfer coefficient to the inlet flow angle for a wavy fin heatexchanger. (Guo and Tafti, 2003) used the inlet flow angle, $\alpha= \pm 25, \pm 45$ and 0 degrees. For positive flow angles which are, in the same direction as the louver angle exhibit better performance characteristics than the negative inlet flow angles. For large negative inlet flow angles, the heat transfer coefficient drops as much as $50 \%$ for a fin pitch equals to $2 \mathrm{~mm}$. 
This relation between the inlet flow angle and the heat exchanger performance will be explored in details for the wavy fin staggered configurations in the present numerical simulation. Also to the best of authors' knowledge, no studies have critically evaluated the effect of inlet flow angle on performance -all studies assume that the flow is normal to the wavy fin-and-tube heat exchanger face.

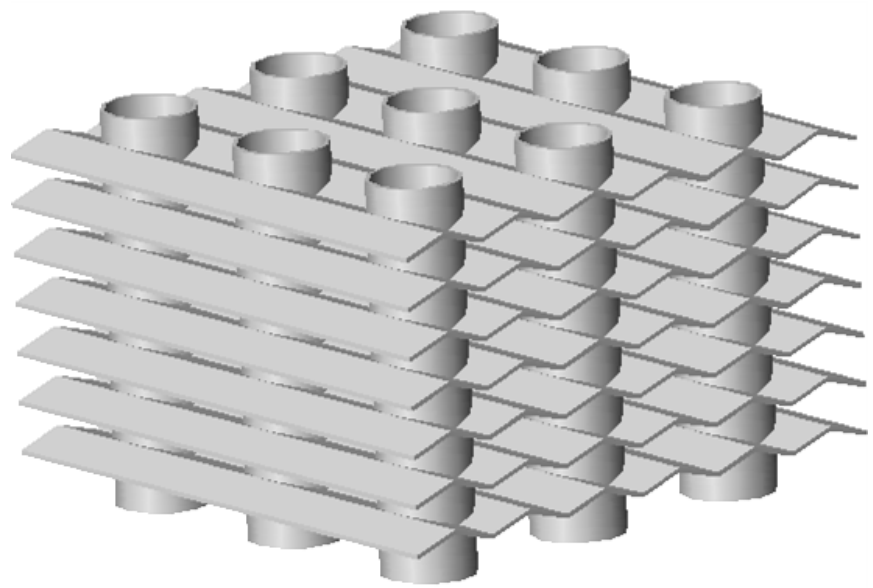

In Lined arrangement

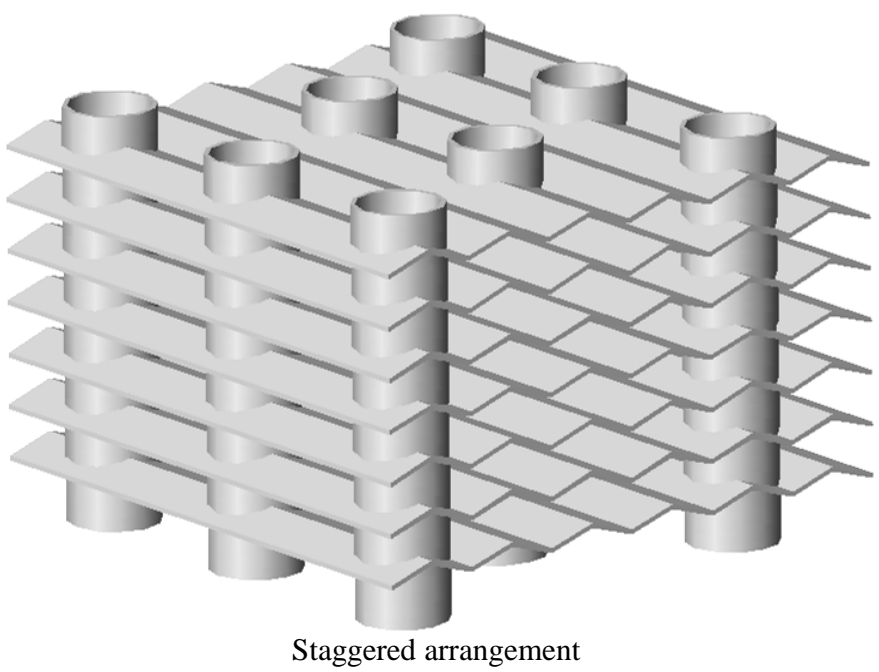

Fig. 1 Tube arrangement of wavy fin-and -tube heat exchanger.

\section{PHYSICAL MODEL AND GOVERNING EQUATIONS}

The present study is based on thermal transport with convective heat transfer for the wavy fin with various tube arrangements as shown in Fig. 1 considering steady 3D incompressible flow. Also no viscous dissipation that means transformation of kinetic energy to internal energy (heating up the fluid) due to viscosity is considered negligible. Air is assumed as the working fluid with constant properties. Flow is considered turbulent and three turbulent models are used namely standard k- $\varepsilon, \mathrm{k}-\omega$ and RNG k- $\varepsilon$ model. The flow is described by the conservation laws for mass (continuity), momentum (Navier-Stokes) and by the energy equations are as follows:

$\frac{\partial u_{i}}{\partial x_{i}}=0$

$\rho\left(\frac{\partial u_{i}}{\partial t}+u_{j} \frac{\partial u_{i}}{\partial x_{j}}\right)=-\frac{\partial p}{\partial x_{i}}+\frac{\partial}{\partial x_{j}}\left[\left(\mu+\mu_{T}\right)\left(\frac{\partial u_{i}}{\partial x_{j}}+\frac{\partial u_{j}}{\partial x_{i}}\right)\right]+\rho g_{i}$

$\rho C_{p}\left(\frac{\partial T}{\partial t}+u_{j} \frac{\partial T}{\partial x_{j}}\right)=\frac{\partial}{\partial x_{j}}\left[\left(\lambda+\frac{\mu_{T} C_{p}}{P r_{T}}\right) \frac{\partial T}{\partial x_{j}}\right]$
Where, $\mu_{\mathrm{T}}$ and $\operatorname{Pr}_{\mathrm{T}}$ are turbulent viscosity and turbulent Prandtl number respectively.

As suggested by (Yuan, 2000), $\operatorname{Pr}_{\mathrm{T}}=0.9$ was used in the current study. The value of $\mu \mathrm{T}$ is determined based on the specific turbulence model that is being used. In $\mathrm{k}-\omega$ turbulent model the $\mu \mathrm{T}$ is linked to the turbulence kinetic energy $(\mathrm{k})$ and turbulence frequency $(\omega)$ via the following relation:

$\mu_{T}=\rho \frac{k}{\omega}$

The transport equations for $\mathrm{k}$ and $\omega$ were first developed by Wilcox [1986] and later it was modified by Menter [1994] can be expressed as:

$\rho\left(\frac{\partial k}{\partial t}+u_{j} \frac{\partial k}{\partial x_{j}}\right)=\frac{\partial}{\partial x_{j}}\left[\left(\mu+\frac{\mu_{T}}{\sigma_{k 3}}\right) \frac{\partial k}{\partial x_{j}}\right]+P_{k}-\beta^{\prime} \rho k \omega$

$\rho\left(\frac{\partial \omega}{\partial t}+u_{j} \frac{\partial \omega}{\partial x_{j}}\right)=\frac{\partial}{\partial x_{j}}\left[\left(\mu+\frac{\mu_{T}}{\sigma_{\omega 3}}\right) \frac{\partial \omega}{\partial x_{j}}\right]+2\left(1-F_{1}\right) \rho \frac{1}{\sigma_{\omega 2} \omega} \frac{\partial k}{\partial x_{j}} \frac{\partial \omega}{\partial x_{j}}+$

$2\left(1-F_{1}\right) \rho \frac{1}{\sigma_{\omega 2} \omega} \frac{\partial k}{\partial x_{j}} \frac{\partial \omega}{\partial x_{j}}+\alpha_{3} \frac{\omega}{k} P_{k}-\beta_{3} \rho \omega^{2}$

In equation (6), $\mathrm{F} 1$ is a blending function and its value is a function of the wall distance. F1 $=1$ and 0 near the surface and inside the boundary layer respectively. The constants of this model $\left(\phi_{3}\right)$ are calculated from the constants $\phi_{1}$ and $\phi_{2}$ based on the following general equation.

$\phi_{3}=F_{1} \phi_{1}+\left(1-F_{1}\right) \phi_{2}$

Details of these different turbulent models are documented in literature (Panse, 2005), (Wilcox, 1986), (Menter, 1994), (Reddy and Gartling, 1994).

The average Nusselt number $\mathrm{Nu}$, defined as:

$\mathrm{Nu}=\frac{\mathrm{h} \cdot \mathrm{H}}{\lambda}$

The friction factor, $\mathrm{f}$ and the Colburn factor, $\mathrm{j}$ are defined as

$\mathrm{f}=\frac{\left(\mathrm{P}_{\text {in }}-\mathrm{P}\right)}{1 / 2 \cdot \rho \cdot \mathrm{u}_{\mathrm{in}}{ }^{2}} \frac{\mathrm{H}}{4 \mathrm{~L}}, \mathrm{j}=\frac{\mathrm{Nu}}{\mathrm{Re}_{\mathrm{H}} \cdot \mathrm{Pr}^{1 / 3}}$

\section{COMPUTATIONAL DETAILS}

\subsection{Domain configuration}

All Our objective is to understand the hydrodynamics of flow and the corresponding heat transfer and pressure drop as a function of the longitudinal pitch ( $\mathrm{Ll})$, transverse pitch( $\mathrm{Lt})$, fin pitch(Fp) and Wavy angle(Wa). The computational domain for the present study is defined by $0 \leqslant X \leqslant 16.16 \mathrm{D}, 0 \leqslant \mathrm{Y} \leqslant 2.66 \mathrm{D}$ and $0 \leqslant \mathrm{Z} \leqslant 0.37 \mathrm{D}$, where tube diameter, $\mathrm{D}=9.525 \mathrm{~mm}$. The volume representing the air which passes through the gap between the two fins is extended downstream from the outlet of the last row cylinder of the heat exchanger for more accurate applications of boundary conditions that is to ensure a representative flow in the computational domain of the actual heat exchanger and to reduce the numerical oscillations. The outlet boundary is thus located 7D downstream of the last row of the cylinder according to Mendez et al, 2000. The nomenclature considered in the present analysis are longitudinal pitch (Ll), transverse pitch (Lt), fin pitch (Fp) or fin spacing $(\mathrm{H})$ and Wavy angle (Wa) as shown in Fig. 2.

\subsection{Coordinate system and boundary conditions}

The All numerical simulations are carried out using a finite-volume method. The boundaries of the computational domain consist of inlet and outlet, symmetry planes and solid walls as illustrated in Fig. 3. Symmetry boundary conditions at the centre plane, tube centre plane, top symmetry and bottom symmetry are considered. Uniform flow with constant velocity $\mathrm{u}_{\mathrm{in}}$ and constant temperature $\mathrm{T}_{\mathrm{in}}$, boundary conditions at the inlet flow is used to trigger the flow unsteadiness in the flow passage. Other velocity components are assumed to be zero. A constant temperature of $25 \mathrm{C}$ is set at the flow inlet to meet the room air conditions. At the outlet, stream wise gradient (Neumann boundary conditions) for all the variables are set to zero. No-slip boundary 
condition is used at the fins and the tube surfaces. These surfaces are assumed to be solid wall with no slip boundary condition and constant wall temperature $\mathrm{T}_{\text {wall }}$ set to $100^{\circ} \mathrm{C}$. The fins and tubes are assumed to be made of aluminium. The heat exchanger model with its extended volume is illustrated in Fig. 3, while the actual area of interest for the heat exchanger simulation is as a computational domain with the coordinates system shown in Fig. 4.
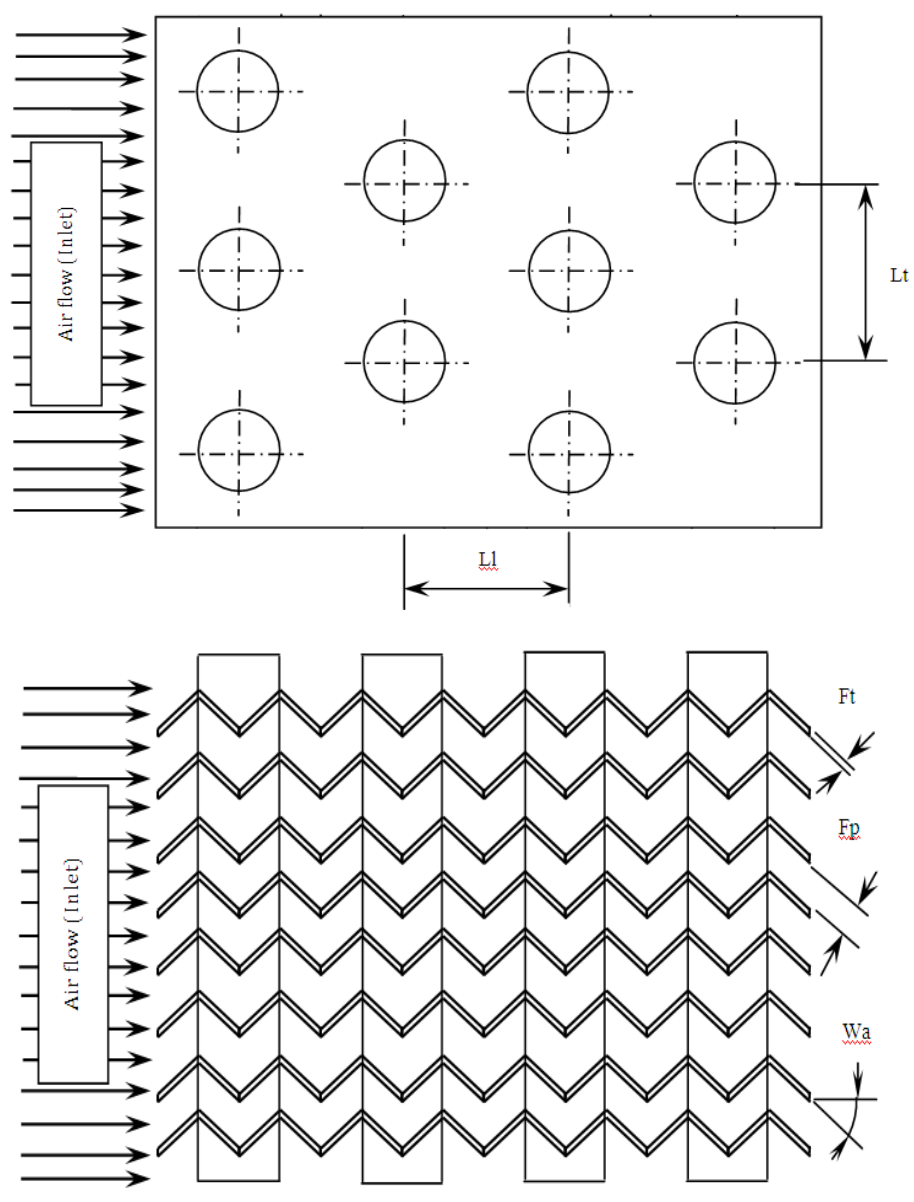

Fig. 2 Details of Nomenclature of wavy fin staggered configuration

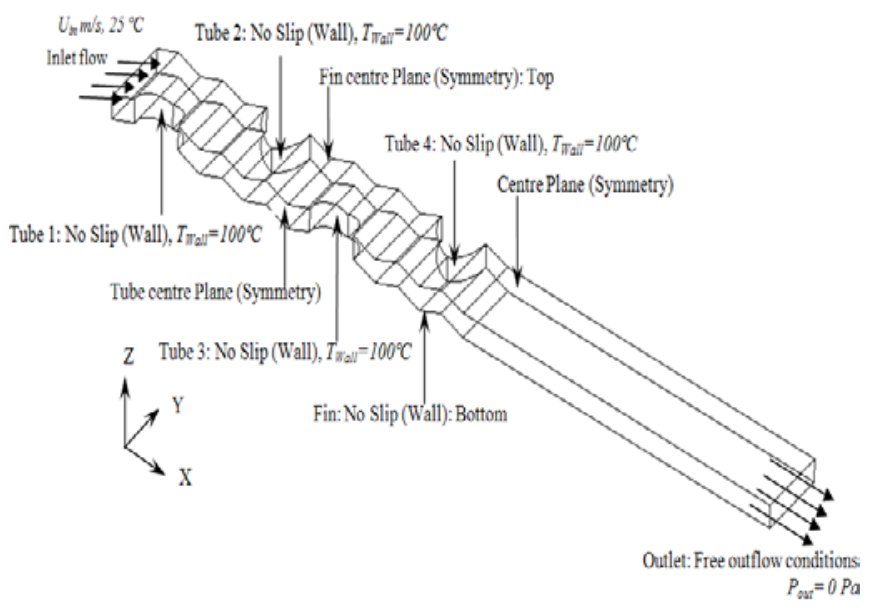

Fig. 3 Boundary conditions of the wavy fin and tube heat exchanger.
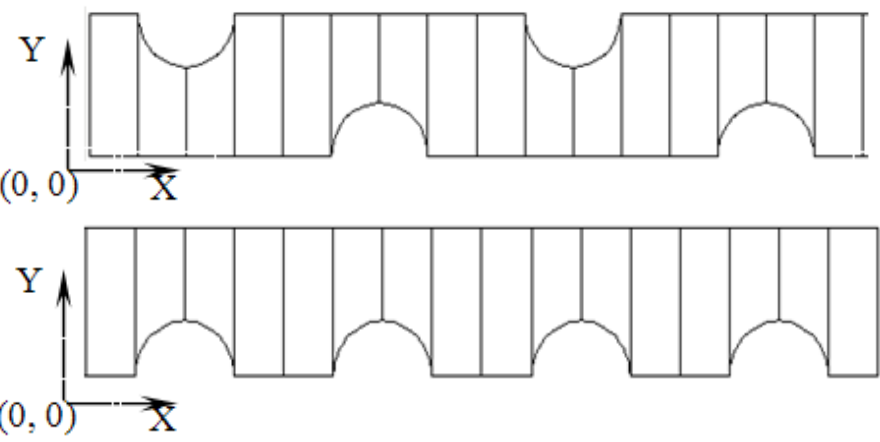

Fig. 4 Computational domain and the Coordinate system

\subsection{Grid Independence}

As the accurateness of the numerical results depends stalwartly on the mesh resolutions, a number of trial simulations were carried out with different mesh resolutions. The three different grid size chosen are 121574, 183223 and 263318 nodes. The variation of friction factor and Colburn factor of the domain are investigated to attain the independence of $\mathrm{f}$ and $\mathrm{j}$ for a given number of nodes. It was observed that an unstructured mesh system with triangular mesh containing 183223 nodes with 451683 elements is considered to be fine enough to resolve the flow features in all simulations.

\subsection{Code validation}
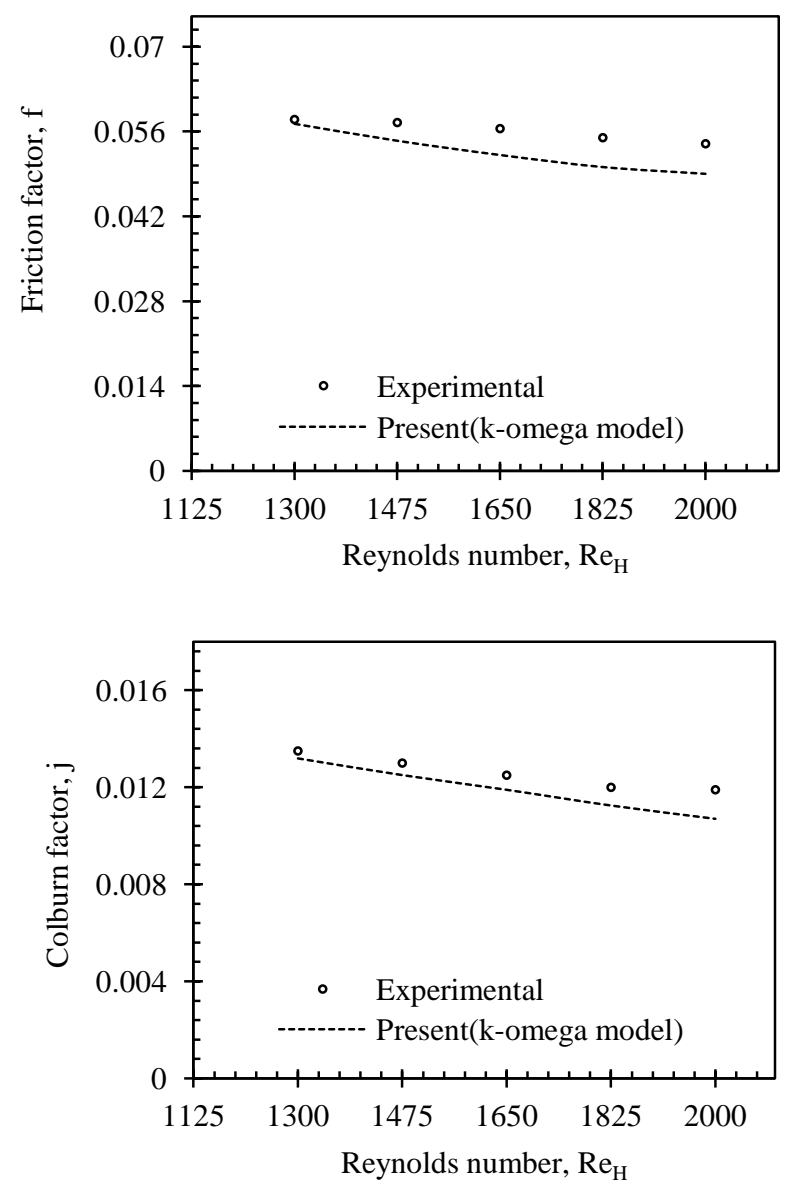

Fig. 5 Comparison between obtained numerical and the experimental data.

To ensure the numerical results are unswerving, calculations were first prepared to scrutinize the recital of wavy fin geometry having 4 rows staggered circular tube configuration with the experimental data 
by (Wang et al., 1997). The detailed geometry of the examined heat exchanger is same as Wang et al. As mentioned earlier that three different turbulent models (k- $\varepsilon$, RNG $\mathrm{k}-\varepsilon$ and $\mathrm{k}-\omega$ model) were tested to settle on the most accurate method for the current analysis. It was found that the numerical results fall within $8 \%$ of the experimentally data for the Colburn factor (j) and the friction factor (f) for the $k-\omega$ model. On the other hand, the difference between experimental data and the numerical results for the $\mathrm{j}$ and $\mathrm{f}$ for the $\mathrm{k}-\varepsilon$ model and RNG $\mathrm{k}-\varepsilon$ model were found to be about $20 \%$ and $25 \%$ respectively. The high difference between experimental data and the numerical results for the $\mathrm{k}-\omega$ model can be explained on the basis on their near wall treatments. The wavy surface created by the tubes will introduce near wall streamline curvatures and adverse pressure gradients. The k-epsilon, the RNG $\mathrm{k}$ epsilon and their near wall treatments used in this study. The basic difference in near wall treatment for the $k-\varepsilon$ model and $k-\omega$ model showed that $\mathrm{k}-\omega$ model is better choice for the transitional flow range modeling for the wavy fin configuration. The graphical presentation is shown in Fig. 5.

\section{RESULTS AND DISCUSSION}

Accurate characterization of the flow friction and heat transfer is very important in rating and sizing of heat exchangers. For the flow feature, the effects of heat transfer and pressure drop between the wavy fin staggered and in lined configurations are studied for the turbulent flow regime. The special effects of different geometrical parameters such as $\mathrm{Ll}, \mathrm{Lt}, \mathrm{Fp}$ and $\mathrm{Wa}$ on the heat transfer and the pressure drop characteristics are investigated. The effects of inlet flow angle are also studied as it has significant effects on the heat transfer and pressure drop characteristics. Flow path for wavy fin is complex as there is wavy corrugation as the flow passes through the domain. The flow interruption is caused by the wavy corrugation and the tubes. So the flow is re-oriented at each of the time when wavy corrugation starts. For this reason, less flow recirculation is observed in the wake of the tubes. This is distinctive flow pattern compared to other fin arrangements. The difference between staggered and in-lined configuration can be observed from the velocity vectors and the streamlines pattern as shown in Figs. 6 and 7 for the staggered and inlined arrangements. For the staggered configurations flow interruption takes place on both sides of the domain. Because of the repeated interruption of the flow due to staggered tube on both sides of the domain, a smaller recirculation zone is observed in the trailing edge of the domain. On the other hand for the in-lined arrangements flow is blocked only on one side of the domain due to the in-lined arrays of the tubes. As all the tubes lie on one side of the domain, flow gets separated into two forms as seen from the figure. These two regions can be free flow regions where there is no tube and the stagnant flow regions in the trailing edge of the tubes. This effect satisfied the answer that higher recirculation zone for the in-lined configuration as compared with the staggered configurations.

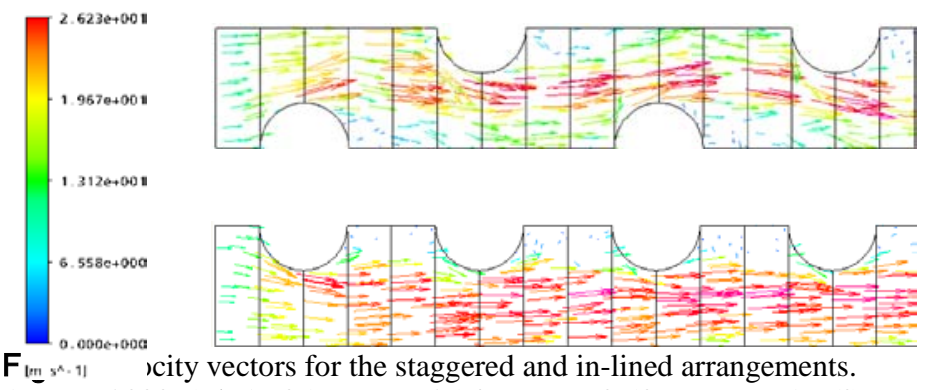

At $\mathrm{Re}_{\mathrm{H}}=2000,\left(\mathrm{Ll}=19.05 \mathrm{~mm}, \mathrm{Lt}=25.4 \mathrm{~mm}, \mathrm{Fp}=3.53 \mathrm{~mm}, \mathrm{Wa}=17.5^{\circ}\right)$
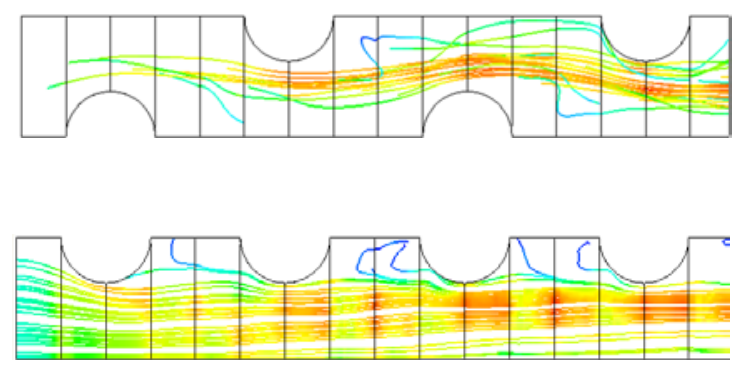

Fig. 7 Streamlines pattern for the staggered and in-lined arrangements At $\mathrm{Re}_{\mathrm{H}}=2000,\left(\mathrm{Ll}=19.05 \mathrm{~mm}, \mathrm{Lt}=25.4 \mathrm{~mm}, \mathrm{Fp}=3.53 \mathrm{~mm}, \mathrm{Wa}=17.5^{\circ}\right)$
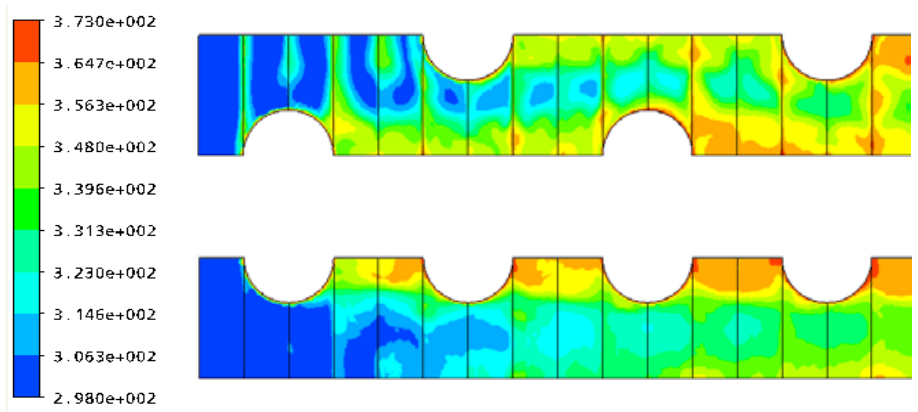

FI. At $\mathrm{Re}_{\mathrm{H}}=2000,\left(\mathrm{Ll}=19.05 \mathrm{~mm}, \mathrm{Lt}=25.4 \mathrm{~mm}, \mathrm{Fp}=3.53 \mathrm{~mm}, \mathrm{Wa}=17.5^{\circ}\right)$

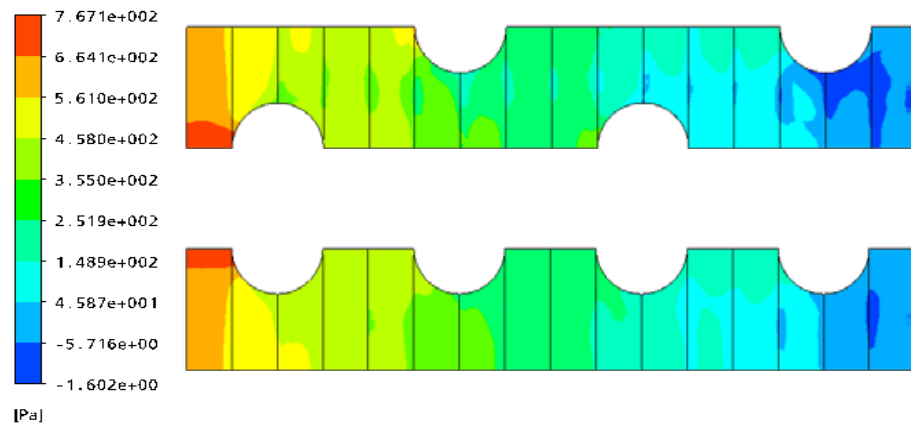

Fig. 9 Pressure distribution for staggered and in-lined arrangements At $\mathrm{Re}_{\mathrm{H}}=2000,\left(\mathrm{Ll}=19.05 \mathrm{~mm}, \mathrm{Lt}=25.4 \mathrm{~mm}, \mathrm{Fp}=3.53 \mathrm{~mm}, \mathrm{Wa}=17.5^{\circ}\right)$

Figures 8 and 9 show the temperature contour and the pressure distribution for the staggered and in-lined arrangements taken on the $\mathrm{X}$ $Y$ planes at $\mathrm{Z}=1.765 \mathrm{~mm}$ for $\mathrm{ReH}=1200$. The temperature profile study provides the same behavior as the streamline pattern and the velocity vector. Much larger recirculation zones are observed in the trailing edge of the tubes for in-lined arrangements as compared to staggered configurations. From the temperature profile of in-lined arrangements, it is found that there is larger high temperature zones in the trailing edge of the tubes can be called warm zones because of the recirculation flow which stretches between two adjacent tubes.

The variation of friction factor (f), Colburn factor (j) and efficiency index $(\mathrm{j} / \mathrm{f})$ against the Reynolds number $(\mathrm{ReH})$ for different tube arrangements in the turbulent flow range are shown in Fig. 10. 

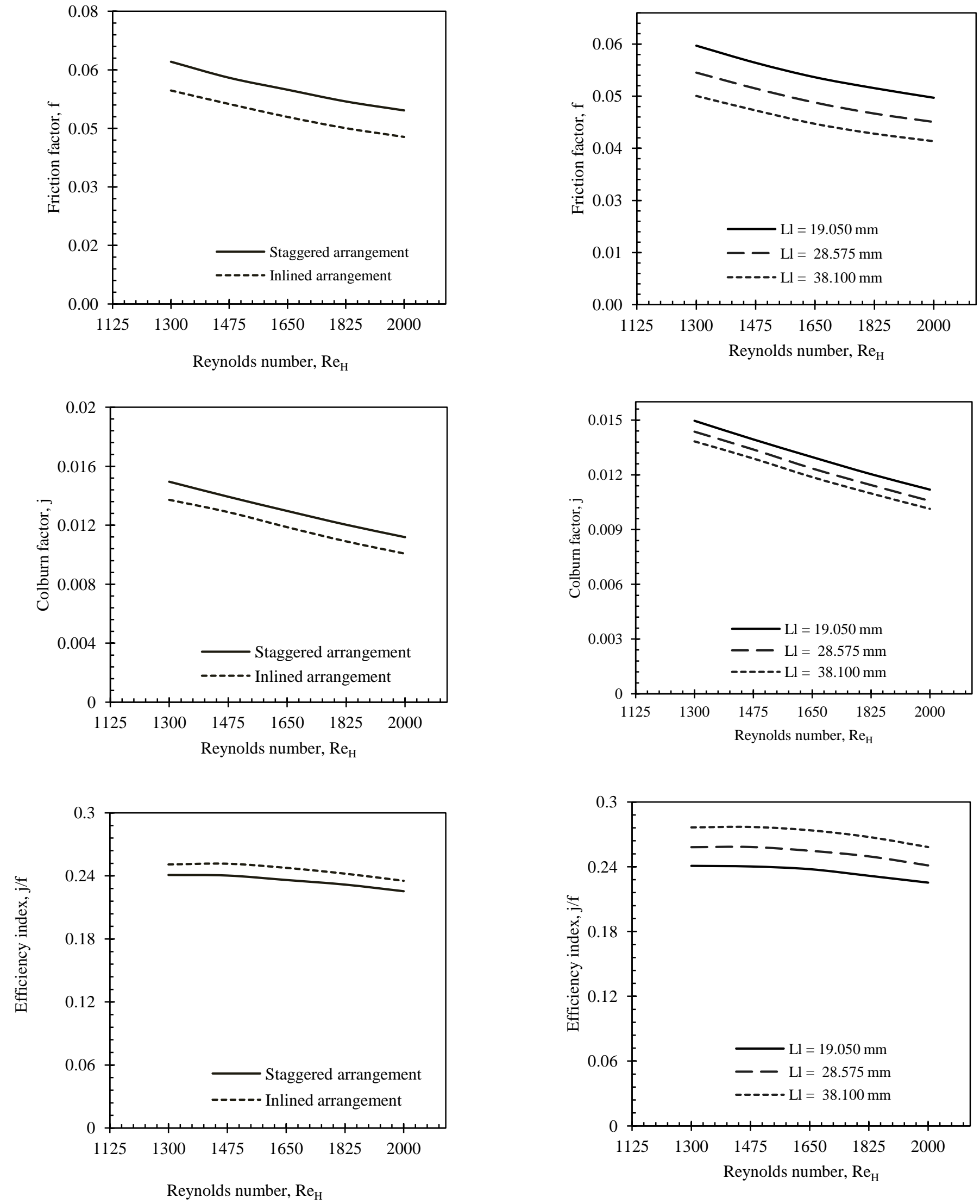

Fig. 10 Performance at staggered \& in lined tube arrangement. $\left(\mathrm{Ll}=19.05 \mathrm{~mm}, \mathrm{Lt}=25.4 \mathrm{~mm}, \mathrm{Fp}=3.53 \mathrm{~mm}, \mathrm{Wa}=17.5^{\circ}\right)$

Fig.11 Effects of longitudinal tube pitch (Ll) for turbulent flow range $\left(\mathrm{Lt}=25.4 \mathrm{~mm}, \mathrm{Fp}=3.53 \mathrm{~mm}, \mathrm{Wa}=17.5^{\circ}\right)$ 

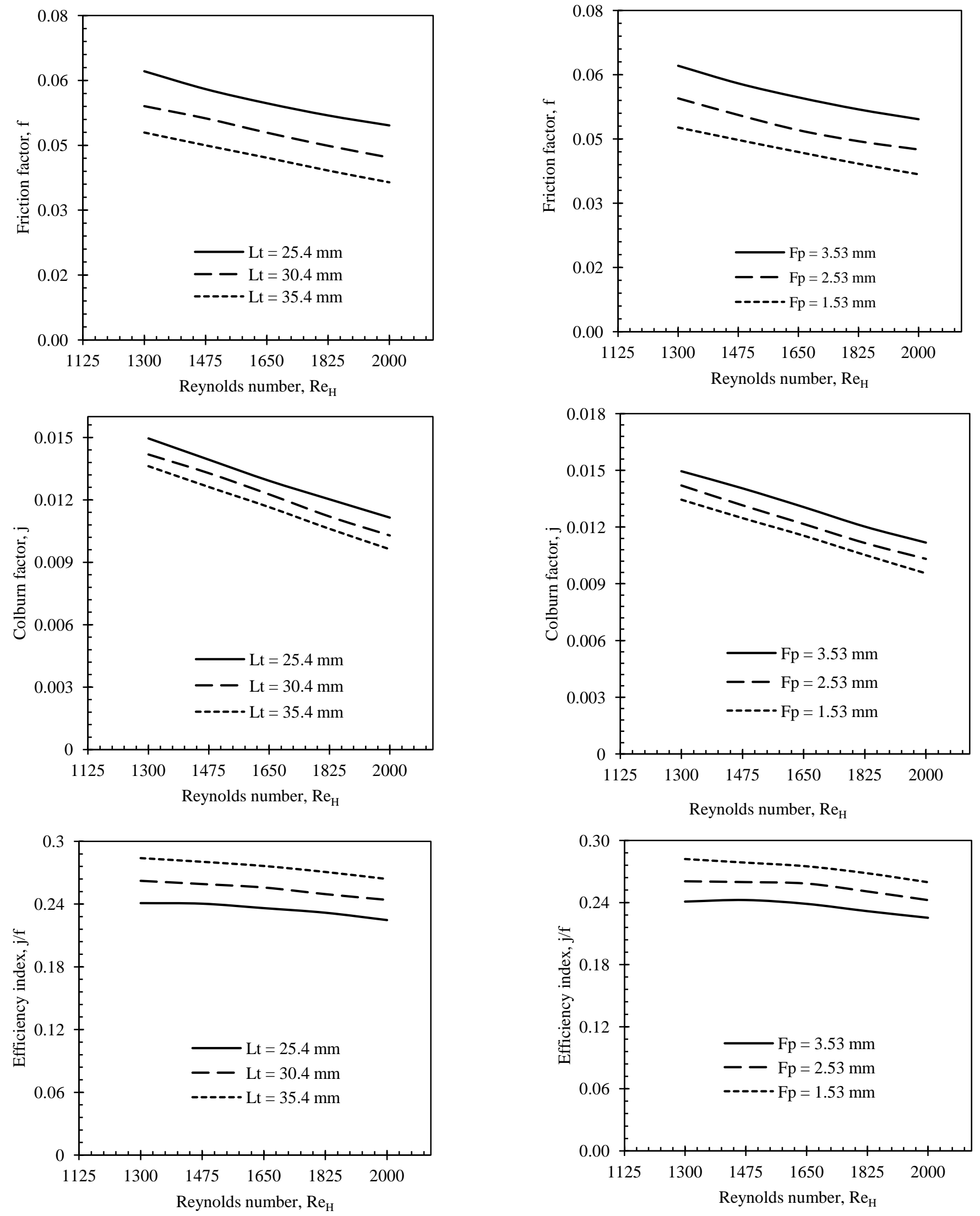

Fig. 12 Effects of transverse tube pitch (Lt) for turbulent flow range. $\left(\mathrm{Ll}=19.05 \mathrm{~mm}, \mathrm{Fp}=3.53 \mathrm{~mm}, \mathrm{Wa}=17.5^{\circ}\right)$

Fig. 13 Effects of fin pitch (Fp) for turbulent flow range. $(\mathrm{Ll}=19.05 \mathrm{~mm}, \mathrm{Lt}=25.4 \mathrm{~mm}, \mathrm{Wa}=17.5)$ 

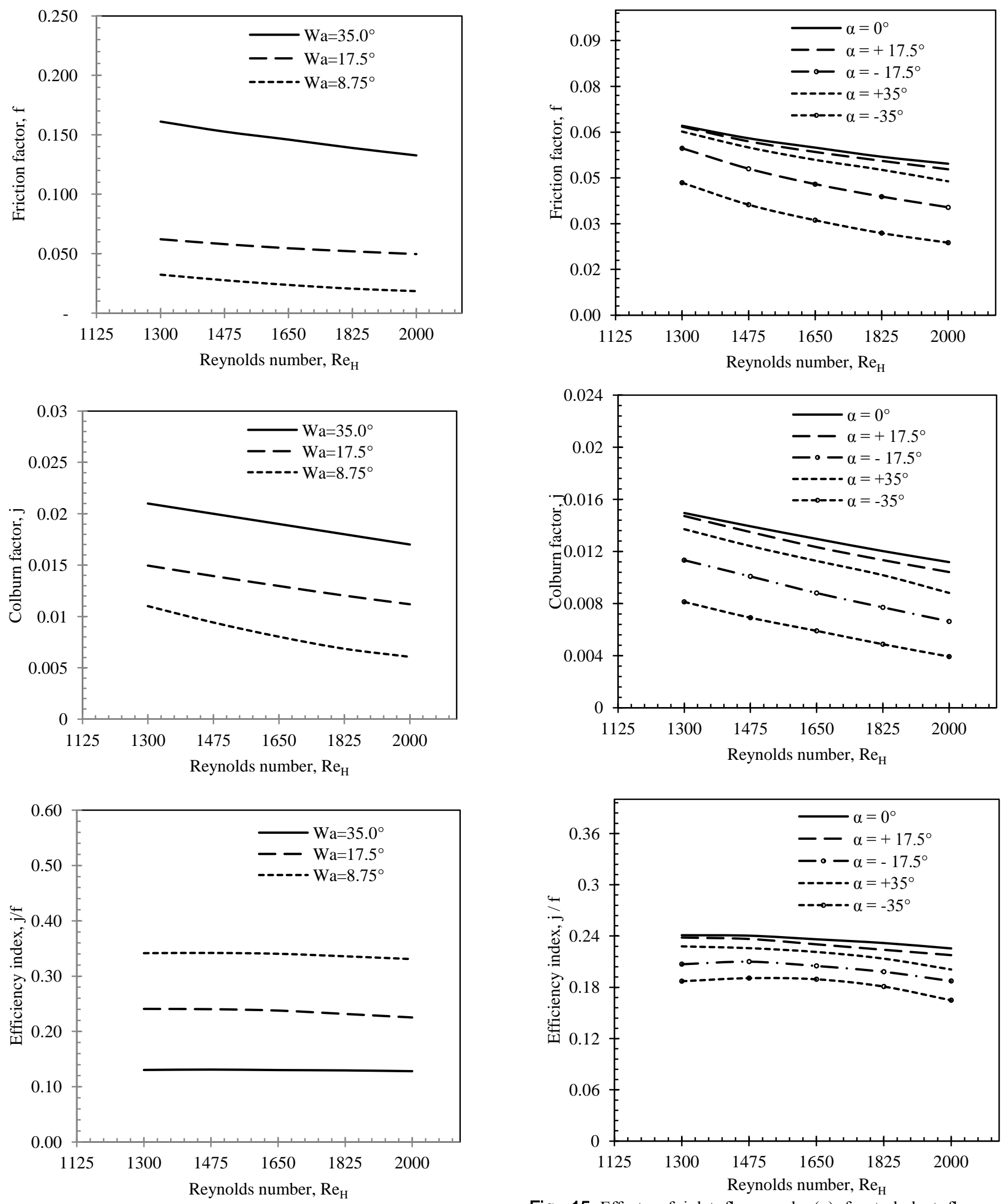

Fig. 14 Effects of wavy angle (Wa) for turbulent flow range. ( $\mathrm{Ll}=19.05 \mathrm{~mm}, \mathrm{Lt}=25.4 \mathrm{~mm}, \mathrm{Fp}=3.53 \mathrm{~mm})$

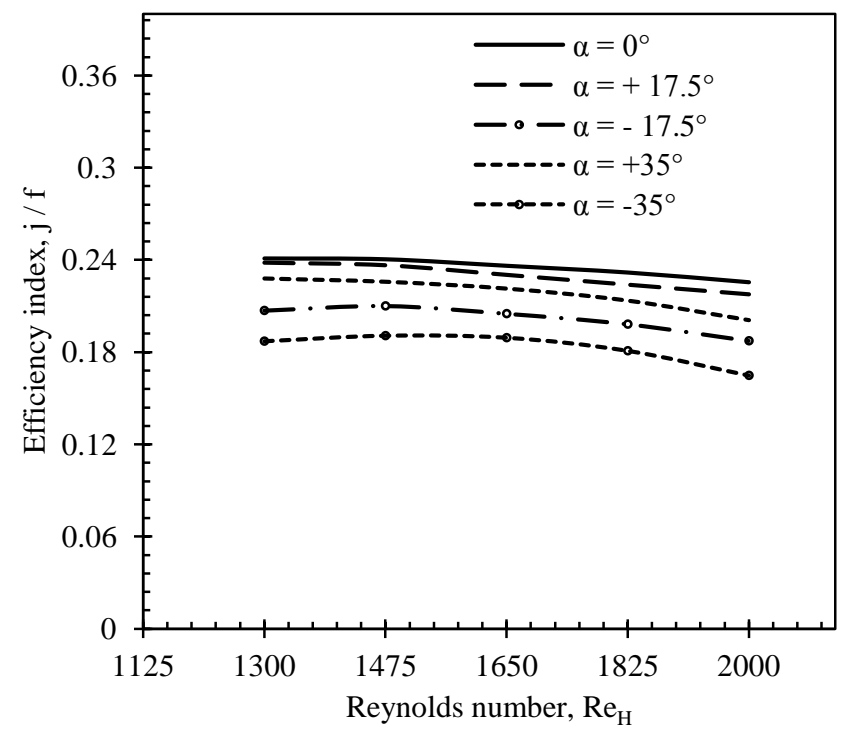

Fig. 15 Effects of inlet flow angle $(\alpha)$ for turbulent flow range. $\left(\mathrm{Ll}=19.05 \mathrm{~mm}, \mathrm{Lt}=25.4 \mathrm{~mm}, \mathrm{Fp}=3.53 \mathrm{~mm}, \mathrm{Wa}=17.5^{\circ}\right)$ 
The variation in $\mathrm{f}$ and $\mathrm{j}$ in case of staggered configuration is $13.17 \%$ $15.88 \%$ and $8.07 \%-10.98 \%$ higher than that of the in-lined arrangements respectively. But the efficiency index (j/f) shows the opposite behavior as the $\mathrm{f}$ and $\mathrm{j}$, as it decreases about $4.02 \%-4.7 \%$ from the in-lined to staggered configuration. It is clear that the tube arrangements play a vital role in the heat transfer and pressure drop characteristics. In staggered arrangements, better flow mixing is observed due to staggered tube layouts and thus provides higher heat transfer and pressure drop characteristics than the in-lined arrangements. So wavy staggered configuration will be considered to investigate the effect of different geometrical parameter in the turbulent range.

Variation of Ll has some effects on $f, j$ and $j / f$ with the increase in $\mathrm{Re}_{\mathrm{H}}$ for turbulent flow range as illustrated in Fig. 11. The graphical presentation indicates that $\mathrm{f}$ decreases with the increase in Ll. For, high velocity at $\mathrm{Re}_{\mathrm{H}}=2000$, $\mathrm{f}$ decreases with the increase in $\mathrm{Ll}$ from 19.05 to $28.575 \mathrm{~mm}$ and 19.05 to $38.10 \mathrm{~mm}$ by $11.67 \%$ and $20.97 \%$ respectively. This statement can be explained that lower the longitudinal pitch $(\mathrm{Ll})$ the surface area is also decreased. So the flow is more restricted and the airflow becomes dense results in higher friction factor. The same behaviour as $\mathrm{f}$ is found for heat transfer. In general, the increase in the heat transfer area would increase the heat transfer. But the current findings contradict this phenomenon. This can be explained that lower the longitudinal pitch, flow is more restricted and the airflow is dense due to close tube spacing and this enhance the heat transfer. But the rate of increase in friction factor is higher than the Colburn factor and as a result the efficiency decrease with the decrease of Ll. The effects of transverse pitch (Lt) on the pressure drop and heat transfer and efficiency for the staggered arrangements are shown in Fig. 12. The effect is very much similar to that of longitudinal pitch.

Figure 13 depicts the effects of fin pitch (Fp) on the $f, j$ and $j / f$. The effect of this is totally different compared to $\mathrm{Ll}$ and Lt. It shows that $\mathrm{f}$ decreases with the decrease in Fp. For the decrease in fin pitch (Fp) from 3.53 to $2.53 \mathrm{~mm}$ and 3.53 to $1.53 \mathrm{~mm}$, f decreases by $14.23 \%$ and $25.89 \%$. Heat transfer performance is quite similar as the pressure drop. This is because when Fp is reduced the flow becomes more streamlined resulting in better flow mixing. Also reduction in the Fp reduces the tube surface area which affects the pressure drop performance. This can also be explained on the basis of boundary layer concept. The boundary layer interruption could not have occurred at large fin pitches with faster inlet air velocities (Higher Reynolds Number). Therefore, the heat transfers for high Reynolds Number were independent of the pitches. However for, smaller fin pitch range with lower inlet velocities, the heat transfer and pressure drop decreased with a reduction in fin pitches. This is because the interruption of the boundary layers between the fins resulted from an increase in the boundary layer thickness with a reduction in fin pitches (inlet air velocity). The enhancement of the $\mathrm{j}$-factor with fin pitches may be the result of the delay of the boundary layer interruption to the next row. Similar results are reported by (Yonghan and Yongchan, 2005) for laminar flow cases.

Wavy angle (Wa) is one of the important parameters in the design of heat exchanger of wavy type. Little attention has given on the performance of different wavy angle in the literature. In the present study, mesmerizing results was observed in the performance of various Wa as shown in Fig. 14.The pressure drop and heat transfer increases with wavy angle for all the fin pitches. The increasing trend is especially significant as Fp is reduced from $3.53 \mathrm{~mm}$ to $1.53 \mathrm{~mm}$. Figure also be evidence for that smaller Fp would result in better heat transfer performance. This is attributable to periodic renewal of the boundary layer. This can be explained that when the wavy angle increased, the length of the wavy corrugation decreased. As a result there are more wavy corrugation for a given flow length. This wavy corrugation provides the flow complexity and better air flow mixing. That's why $f$ and $j$ increases with the increase in Wa. But $j / f$ increase with the decrease in Wa. With the increase in Wa, twice and four times from 8.75 the decrease in $\mathrm{j} / \mathrm{f}$ is about $40.45 \%$ and $74.47 \%$ respectively. This is totally a momentous change. Due to increase in the wavy angle the heats transfer performance increase. At the same time $f$ increases. But $\mathrm{j} / \mathrm{f}$ decrease, because of the drastic increase in pressure drop compared to heat transfer.

The special effects of inlet flow angle on the heat transfer and pressure drop distinctiveness are investigated in this study. The effects of flow angle on the flow efficiency, $f$ and $j$ show similar trend in the turbulent flow as the laminar. With the increase in inlet flow angle which is in the same direction as the wavy angle called positive flow angle, the effects in the heat transfer and pressure drop is decreased. Again, with the decrease in inlet flow angle which is in the negative direction as the wavy angle called negative flow angle, the effects in those criteria is same. But the decrease for the negative flow angle is higher compared to the positive flow angle. The variation of $f, j$ and $j / f$ against $\mathrm{ReH}$ for different inlet flow angle are presented in Fig. 15. Five different inlet flow angle $(\alpha)$ such as $0^{\circ},+17.5^{\circ},-17.5^{\circ},+35^{\circ}$ and $-35^{\circ}$ are considered in the present study. The decrease in $\mathrm{f}$ and $\mathrm{j}$ with $(+\alpha)$ from $0^{\circ}$ to $+17.5^{\circ}$ and $0^{\circ}$ to $+35^{\circ}$ are $3.56 \%, 11.51 \%$ and $6.92 \%$ and $20.21 \%$ while with $(-\alpha)$ these are $28.78 \%, 52.08 \%$ and $40.81 \%$ and $64.96 \%$ respectively at point, $\mathrm{Re}_{\mathrm{H}}=2000$. Figure also shows the dissimilarity of $\mathrm{j} / \mathrm{f}$ against $\mathrm{Re}_{\mathrm{H}}$ for different inlet flow angle. For a particular Reynolds number of $\mathrm{Re}_{\mathrm{H}}=2000$, the decrease in the efficiency index $\mathrm{j} / \mathrm{f}$ with the negative flow angle are more significant compared to positive flow angles.

\section{CONCLUSION}

Numerical visualisations are used to study the thermal and hydraulic performance of four row wavy staggered fin and tube heat exchanger. In this paper, the effects of tube arrangements, different geometrical parameters and inlet flow angles are investigated in terms of heat transfer and pressure drop and efficiency for the wavy fin-and-tube heat exchanger for turbulent flow regime using $k-\omega$ turbulence model with $5 \%$ turbulence intensity. The tube arrangement and the geometrical parameters such as pitch, wavy angle and inlet flow angle have strongly affected the flow structure. Comparatively higher heat transfer and pressure drop is found in staggered arrangement than in lined for both laminar and turbulent case. By increasing $\mathrm{Ll}$ and Lt, $\mathrm{f}$ and $\mathrm{j}$ both decreases as the flow becomes free and less compact. But efficiency goes high. The fin spacing very strongly influences the heat transfer and pressure drop. If it is too small, the effects are less; if it is too large, the effect is comparatively higher. Higher pressure drop and heat transfer are observed for more inclination in a given flow length, but efficiency decrease with the increase in the wavy angle. With the increase in positive flow angle, the effects in the heat transfer and pressure drop is decreased. Again, with the increase in negative flow angle, the effect in those criteria is same. But the decrease for the negative flow angle is higher compared to the positive flow angle.

\section{REFERENCES}

Ali, M. M. and Ramadhyani, S., 1992, "Experiments on Convective Heat Transfer in Corrugated Channels," Experimental Heat Transfer, 5(3), 175-193.

http://dx.doi.org/10.1080/08916159208946440

Amano, R. S., 1985, "Numerical Study of Laminar and Turbulent Heat Transfer in a Periodically Corrugated Wall Channel," Journal of Heat Transfer, Transactions ASME, Vol. 107(3), 564-569.

http://dx.doi.org/10.1115/1.3247461

Asako, Y., and Faghri, M., 1987, "Finite-Volume Solutions for Laminar Flow and Heat Transfer in a Corrugated Duct ," Journal of Heat Transfer, Transactions ASME, 109(3), 627-634.

http://dx.doi.org/10.1115/1.3248134

Beecher, D. T. and Fagan, T. J., 1987, "Effects of Fin Pattern on the Air Side Heat Transfer Coefficient in Plate Finned-tube Heat Exchangers," ASHRAE Transactions, 93(2), 1961-1984.

Guo, D. and Tafti, D. K., 2003, "Effect of Inlet Flow Angle on Performance of Multi-louvered Fin Heat Exchangers," American Society of Mechanical Engineers, Heat Transfer Division, (Publication) HTD, 374(1), 103-109. 
K. Yonghan, K. Yongchan, 2005, "Heat Transfer Characteristics of the Flat Plate Finned-tube Heat Exchangers with Large Fin Pitch," International Journal of Refrigeration, 28, 851-858 http://dx.doi.org/10.1016/j.ijrefrig.2005.01.013

Jang, Y. J., Wu, M. C. and Chang, W. J., 1997, "Numerical and Experimental Studies of Three Dimensional Wavy-fin and Tube Heat Exchangers," International Journal of Heat and Mass Transfer, 39(14), 3057-3066.

http://dx.doi.org/10.1016/0017-9310(95)00341-X

Kays, W. M. and London, A. L., 1984, Compact Heat Exchangers, 3rd Edition, McGraw-Hill, New York.

Kim, N. H., Youn, J. H. and Webb, R. L.,1996, " Heat Transfer And Friction Correlations For Wavy Plate Fin-and-tube Heat Exchangers," American Society of Mechanical Engineers, Heat Transfer Division, (Publication) HTD, 330(8), 43-52,.

McNab, C. M., Atkinson, K. N., Heikal, M. R. and Taylor, N., 1996, "Numerical Modeling of Heat Transfer and Fluid Flow Over Herringbone Corrugated Fins," Proceedings of the 11th International Heat Transfer Conference, Kyongiu, Korea, 6, 119-124.

Menter, F. R.,1994, “Two-equation Eddy-Viscosity Turbulence Models For Engineering Applications,” AIAA Journal, 32(8), 1598-1605. http://dx.doi.org/10.2514/3.12149

Nishimura, T., Yoshino, T. and Kawamura, Y., 1987, "Numerical Flow Analysis of Pulsatile Flow in a Channel with Symmetric Wavy Walls at Moderate Reynolds Numbers," Journal of Chemical Engineering of Japan, 20(5), 479-485.

http://dx.doi.org/10.1252/jcej.20.479

Panse, S. P., 2005, “A Numerical Investigation of Thermal and Hydraulic Characteristics in 3D Plate and Wavy Fin-tube Heat Exchangers for Laminar and Transitional Flow Regimes," M. Sc. Thesis, Montana State University, Bozeman, Montana, USA.

Patel, V. C., Chon, J. T. and Yoon, J. Y., 1991, "Turbulent Flow in a Channel with a Wavy Wall," Journal of Fluids Engineering, Transactions of the ASME, 113(4), 579-586. http://dx.doi.org/10.1115/1.2926518

Reddy and Gartling, 1994, The Finite Element Method in Heat Transfer and Fluid Dynamics, CRC Press, Inc., Boca Raton.

Rutledge, J. and Sleicher, C. A., 1994, "Direct Simulation of Turbulent Flow and Heat Transfer in a Channel Part II: A Green's Function Technique for Wavy Walls," Communications in Numerical Methods in Engineering, 10(6), 489-496.

http://dx.doi.org/10.1002/cnm.1640100608

R. R. Mendez, M. Sen, K. T. Yang, and McClain, R., 2000, "Effect of fin Spacing on Convection in a Plate Fin and Tube Heat Exchanger," International Journal of Heat and Mass Transfer, 43, 39-51.
http://dx.doi.org/10.1016/S0017-9310(99)00120-9

Snyder, B., Li, K. T. and Wirtz, R. A., 1993, "Heat Transfer Enhancement in a Serpentine Channel," International Journal of Heat and Mass Transfer, 36(12), 2965-2976. http://dx.doi.org/10.1016/0017-9310(93)90026-3

Wang, C. C., Fu, W. L. and Chang, C. T., 1997, "Heat Transfer and Friction Characteristics of Typical Wavy Fin-and-Tube Heat Exchangers," Experimental Thermal and Fluid Science, 14(2), 174-186. http://dx.doi.org/10.1016/S0894-1777(96)00056-8

Wang, C. C., Wu, M. C. and Chang, C. T.,1995, "Finned Tube Heat Exchangers: Wavy Fin Geometry," Proceedings of Asia Pacific Conference on Built Environment, Singapore, 1, 194-204.

Wang, C. C., Hwang, Y. M. and Lin, Y. T., 2002, "Empirical Correlations for Heat Transfer and Flow Friction Characteristics of Herringbone Wavy Fin-and-tube Heat Exchangers," International Journal of Refrigeration, 25(5), 673-680. http://dx.doi.org/10.1016/S0140-7007(01)00049-4

Wang, C. C., Tsi, Y. M. and Lu, D. C., 1998, "Comprehensive study of convex-louver and wavy fin-and-tube heat exchangers" Journal of Thermophysics and Heat Transfer, 12(3), 423-430.

Wang, C. C., Lin, Y. T., Lee, C. J. and Chang, Y. J.,1999, "Investigation of Wavy Fin-and-Tube Heat Exchangers: A Contribution to Databank,” Experimental Heat Transfer, 12(1), 73-89.

http://dx.doi.org/10.1080/089161599269825

Wilcox, D. C., 1986, "Multi-Scale Model for Turbulent Flows,” AIAA 24th Aerospace Sciences Meeting, American Institute of Aeronautics and Astronautics.

Xin, R. C. and Tao, W. Q., 1988, "Numerical Prediction of Laminar Flow and Heat Transfer in Wavy Channels of Uniform Cross-Sectional Area," Numerical Heat Transfer, 14(4), 465-481.

Yan, W. M., Sheen, P. J., 2000,"Friction Heating Analysis of Piston Rod of Shock Absorber and The Correlation between Temperature and Hardness,” International Journal of Heat and Mass Transfer, 43(9), 1651-1659. http://dx.doi.org/10.1016/S0017-9310(99)00229-X

Yang, L. C., Asako, Y., Yamaguchi, Y. and Faghri, M., 1997, "Numerical Prediction of Transitional Characteristics of Flow and Heat Transfer in a Corrugated Duct,” ASME Journal of Heat Transfer, 119, 62-69.

http://dx.doi.org/10.1115/1.2824101

Yuan, Z. X., 2000, "Numerical Study of Periodically Turbulent Flow and Heat Transfer in a Channel with Transverse Fin Arrays," International Journal of Numerical Methods for Heat and Fluid Flow, 10(8), 842-86.

http://dx.doi.org/10.1108/09615530010359139 